\title{
Is Sufficiency in Food Alone- A Guarantee of An End of Hunger? Evidences from Rural Bangladesh
}

\author{
Md. Touhidul Alam \\ Dhaka School of Economics, University of Dhaka, Bangladesh
}

\begin{abstract}
Food security refers to proper access to sufficient and nutritious food. Despite the claim that Bangladesh is self sufficient in food, the real scenario, as evident, is that a big portion of our population lack in sufficient calorie. An attempt has been made through this study to determine the causes of this lack in sufficient calorie i.e., food insecurity in rural Bangladesh by using data from the project "Chronic poverty in Rural Bangladesh-2009". A Binary Logistic Regression model has been used to investigate determinants of food insecurity. Households are defined as food insecure ${ }^{(1)}$ if calorie consumption per day per capita is less than $2122 \mathrm{kcal}$ and food secure ${ }^{(0)}$ otherwise. From our investigation and empirical analysis it is found that despite of having increasing trend both in per capita food production and food availability, many of our people lack in energy balance. That is, sufficiency of food alone doesn't guarantee an end of hunger. Household size, dependency ratio, land assets of the households and per capita monthly income are found statistically significant for such an imbalance. Moreover, result from Receiver Operating Characteristic (ROC) curve suggests that our fitted model is fairly discriminating.
\end{abstract}

Keywords: Determinants, Food insecurity, Logistic Regression Model, ROC curve, Rural Bangladesh

\section{Introduction}

Food security is a complex issue and its drivers are interdependent. In the context of rural Bangladesh, food security may be affected by factors ranging from drought and flood to landlessness, household size, per capita income etc. When analyzing trend in food grain (rice and wheat) production in Bangladesh, and her demand and a deduction of 12 percent of the production for seed, feed and wastages, it is apparent that Bangladesh should have achieved food self-sufficiency since 2005-06 and was supposed to be endowed with surplus of food [1].

But, in its Household Income and Expenditure Survey (HIES) 2005, Bangladesh Bureau of Statistics (BBS) estimated that about $40 \%$ of Bangladesh's total population were calorie poor, consuming less than 2122 kcal per capita per day. This reveals that despite of large scale of food production (mostly rice), a large portion of our people failed to have sufficient food intake.

However, poverty estimate based on Direct Calorie Intake (DCI) method was not carried out in HIES'2010 by BBS. This kept us in the dark to ascertain with what portion of population is still energy imbalance in recent past. But, different reports that assess Millennium Development Goals (MDGs) in the context of Bangladesh are found cynical in achieving the MDG target-1 of halving population of proportion below minimum level of dietary energy consumption $(2122 \mathrm{kcal})$ to 24 percent in 2015 from 48 percent of its base year of 1990/91 [2]. Hence, it is a clarion call to assess why our people have been still suffering from energy imbalance (energy intake is lower than energy requirement). So, we need to probe the problem of food insecurity and find out factors that impede households to be food secure.

\section{Overview of Food Insecurity} in Table1.

The indicators of food security can be found from household survey data [3]. These indicators are listed

Table 1: Indicators of food security and their household-level measures

\begin{tabular}{l|l}
\hline Population level indicators & Household level measure \\
\hline Diet quantity & Household daily food energy availability per capita. \\
\hline Daily food energy consumption per capita & $\begin{array}{l}\text { Whether a household is food energy-deficient (An individual's energy- } \\
\text { deficiency situation is defined as that of her or his household.) }\end{array}$ \\
\hline $\begin{array}{l}\text { Percentage of households or people that are food } \\
\text { Dergy-deficient }\end{array}$ & $\begin{array}{l}\text { Household diet diversity. The number of foods or nutritionally } \\
\text { significant food groups acquired by a household over the reference } \\
\text { period }\end{array}$ \\
\hline Diet diversity & \multicolumn{2}{l}{} \\
\hline
\end{tabular}




\begin{tabular}{l|l}
\hline Percentage of food energy from staples & $\begin{array}{l}\text { Percentage of food energy available from staples. The percentage of the } \\
\text { energy acquired by a household over the reference period that is derived } \\
\text { from staple foods }\end{array}$ \\
\hline Quantities of foods consumed daily per capita & $\begin{array}{l}\text { Quantities of foods acquired daily per capita. Quantity of specific foods } \\
\text { acquired over the reference period } \\
\text { divided by the number of household members and the number of days in } \\
\text { the period. }\end{array}$ \\
\hline Current Economic vulnerability & $\begin{array}{l}\text { Percentage of expenditures on food. The percentage of total household } \\
\text { expenditures devoted to food over } \\
\text { the reference period }\end{array}$ \\
\hline
\end{tabular}

Source: [3]

In this study, the indicator- daily food energy consumption per capita has been taken into account for measuring household's food insecurity. Again, Table 2 shows how the concept of food insecurity has been converted into explained variable.

Table 2: Converting concept into variable

\begin{tabular}{l|l|l|l}
\hline Concept & Indicator & Variable (Explained) & Decision level (working definition) \\
\hline Food insecurity & $\begin{array}{l}\text { Daily food energy consumption } \\
\text { per capita }\end{array}$ & Per capita Kcal intake & If $<2122$ Kcal $\rightarrow$ food insecure \\
\hline
\end{tabular}

Source: Author's compilation based on FAO suggestions for the South Asian countries

\section{Source of Data}

The data used in this study has been taken from the survey under the research project "Chronic poverty in Rural Bangladesh-2009” carried out by Professor P.K. Motiur Rahman, Institute of Statistical Research and Training, University of Dhaka. The survey was carried out during January 28 - February 28, 2010 on 1,212 rural households selected at random from 32 villages spread over rural areas of 8 poverty prone districts. In its sampling design, a three-stage stratified random sampling design was followed for selecting the final sampling unit (FSU). At the first stage, eight of the most vulnerable and least developed districts were selected. At the second stage, 32 villages were selected at random and at the third stage, households were selected at random. At the third stage, the criterion of stratification was the economic status of households, i.e. (i) non-poor, (ii) descending non-poor (iii) ascending poor and (iv) chronically poor.

However, in selecting the least developed district, a composite index was computed on the basis of three simple indicators such as percentage of agricultural labor, landless households, and cropping intensity [4].

\subsection{Explained Variable}

\section{List of Variables Used}

As specified in Table 2, the explained variable is per capita kilo calorie intake. This study defines households as food insecure ${ }^{(1)}$ if calorie consumption per day per capita is less than $2122 \mathrm{kcal}$ and food secure ${ }^{(0)}$ otherwise.

\subsection{Explanatory Variables}

Based on existing literature, this study chooses explanatory variables as - Sex of Household Head, Household Size, Average Schooling Years of Households, Dependency Ratio, Household's Ownership of Landed Assets, Membership to NGO/Samity, Access to Safety Net Programs, Per Capita Monthly Income (median), Occupation of Household Head and Access to electricity.

\section{Statistical Tools Employed}

To investigate the measure of association, chi-square test has been used. Later on, the Binary Logistic Regression Model has been used to assess factors associated with food insecurity. At last, area under Receiver Operating Characteristic (ROC) curve has been used to ascertain discriminatory performance of the fitted model.

However, in fitting logistic regression, we may assume a collection of $\mathrm{p}$ explanatory variables denoted by $\mathrm{X}=\left(\mathrm{X}_{\mathrm{i} 1}, \mathrm{X}_{\mathrm{i} 2}, \ldots \ldots \ldots \mathrm{X}_{\mathrm{ip}}\right)$. let $\mathrm{Y}$ be the dichotomous explained variable which takes values 1 \& 0 i.e.,

$$
\begin{gathered}
Y_{i}=\left\{\begin{array}{l}
1, \text { if the household is food insecure } \\
0, \text { if otherwise } \\
\text { for } i=1,2, \ldots \ldots \ldots \ldots \ldots . n
\end{array}\right.
\end{gathered}
$$

Now, we can define,

$$
\pi\left(\mathrm{x}_{\mathrm{i}}\right)=\mathrm{p}\left(\mathrm{y}_{\mathrm{i}}=1 / \mathrm{X}\right)=\frac{\exp \left(\beta_{0}+\beta_{1} x_{i 1}+\beta_{2} x_{i 2}+\cdots+\beta_{p} x_{i p}\right)}{1+\exp \left(\beta_{0}+\beta_{1} x_{i 1}+\beta_{2} x_{i 2}+\cdots+\beta_{p} x_{i p}\right)}
$$


$=$ conditional probability that the households are food insecure

again, $1-\pi\left(\mathrm{x}_{\mathrm{i}}\right)=\mathrm{p}\left(\mathrm{y}_{\mathrm{i}}=0 / \mathrm{X}\right)=\frac{1}{1+\exp \left(\beta_{0}+\beta_{1} x_{i 1}+\beta_{2} x_{i 2}+\cdots+\beta_{p} x_{i p}\right)}$

$=$ conditional probability that the households are not food insecure.

Now, the logistic response function can be easily linearized. Logistic regression model, being a part of generalized linear model (GLM), can be linearized with the help of a link function. The approach defines structural portion of the model in terms of a function of the response function mean. Let,

$$
\eta=\beta_{0}+\beta_{1} x_{i 1}+\beta_{2} x_{i 2}+\cdots+\beta_{p} x_{i p}
$$

be the linear predictor where $\eta$ is defined by the transformation

$$
\eta=\ln \frac{\pi\left(x_{i}\right)}{1-\pi\left(x_{i}\right)}
$$

This transformation is called the logit transformation. This is also known as log odds.

Now, we may describe the response probability as

$$
\operatorname{Pr}\left(y_{i}=1 / x\right)=\Lambda\left(\beta^{\prime} x\right)
$$

Where $\Lambda\left(\beta^{\prime} x\right)$ is the cumulative logistic function with values on interval $[0,1]$ for all real numbers.

To have effect of $\Delta x_{k}$ on response probability $\operatorname{Pr}\left(y_{i}=1 / x\right)$, we have

This is often known as marginal effect.

$$
\frac{\delta \operatorname{Pr}\left(y_{i}=1 / x\right)}{\delta x_{k}}=\frac{\delta \Lambda\left(\beta^{\prime} x\right)}{\delta x_{k}}=\frac{e^{\beta^{\prime} x}}{\left(1+e^{\beta^{\prime} x}\right)^{2}} \beta_{k}
$$

\section{Empirical Findings}

Estimated results from bi-variate analysis have been presented in Table 3. It is observed that all variables except membership of $\mathrm{NGO} /$ samity are associated with food insecurity. As per screening criterion, a

\begin{tabular}{|c|c|c|c|}
\hline Explanatory variables & Food insecurity (\%) & $p$-value & Comments \\
\hline $\begin{array}{l}\text { Sex of Household Head } \\
\text { Mate } \\
\text { Female } \\
\end{array}$ & $\begin{array}{l}51.1 \\
58.3 \\
\end{array}$ & 0.132 & Should be included in the model \\
\hline $\begin{array}{l}\text { Household Size }{ }^{\text {Cat }} \\
<5 \text { members } \\
5-6 \text { members } \\
>6 \text { members }\end{array}$ & $\begin{array}{l}44.5 \\
56.4 \\
57.1\end{array}$ & $<0.001$ & Should be included in the model \\
\hline $\begin{array}{l}\text { Household Ownership of Landed Assets } \\
\text { Landless } \\
\text { Small farmers }(.05-2.49 \text { acres }) \\
\text { Medium \& large farmers }(>2.49 \text { acres })\end{array}$ & $\begin{array}{l}67.9 \\
52.9 \\
32.9 \\
\end{array}$ & $<0.001$ & Should be included in the model \\
\hline $\begin{array}{l}\text { Membership of any NGO/ Samity }{ }^{\text {Cat }} \\
\text { Yes } \\
\text { No }\end{array}$ & $\begin{array}{l}51.7 \\
51.9 \\
\end{array}$ & 0.934 & Should not be included in the model \\
\hline $\begin{array}{l}\text { Access to (VGD/VGF/FFA) }{ }^{\text {Cat }} \\
\text { Yes } \\
\text { No }\end{array}$ & $\begin{array}{c}55 \\
50.6 \\
\end{array}$ & 0.143 & Should be included in the model \\
\hline $\begin{array}{l}\text { Per Capita Monthly Income (median) }{ }^{\text {Cat }} \\
<1178 \mathrm{Tk} . \\
\geq 1178 \mathrm{Tk} .\end{array}$ & $\begin{array}{l}67.9 \\
35.5 \\
\end{array}$ & $<0.001$ & Should be included in the model \\
\hline $\begin{array}{l}\text { Occupation of Household Head } \\
\text { Agriculture } \\
\text { Labor(agri+nonagri) } \\
\text { Service } \\
\text { Business } \\
\text { Others } \\
\end{array}$ & $\begin{array}{c}43 \\
65 \\
44 \\
51.6 \\
54.8 \\
\end{array}$ & $<0.001$ & Should be included in the model \\
\hline $\begin{array}{l}\text { Access to Electricity }{ }^{\text {Cat }} \\
\text { Yes } \\
\text { No }\end{array}$ & $\begin{array}{l}43.5 \\
56.9 \\
\end{array}$ & $<0.001$ & Should be included in the model \\
\hline Dependency Ratio ${ }^{\text {Con }}$ & & $<0.001$ & Should be included in the model \\
\hline Average Schooling Years of Households ${ }^{\text {Con }}$ & & 0.029 & Should be included in the model \\
\hline
\end{tabular}
variable is a candidate for the multivariate model when its $p$-value $<0.25$ [5]. A relatively high significance level is chosen not to miss any possible variable associated with food insecurity.

Table 3: Distribution of food insecurity by explanatory variables and their relevant significance

Note: Cat stands for Categorical variables \& Con stands for Continuous variables

To identify factors that affect food security of a household and determine the direction of their differentials between food secure \& insecure groups, multivariate logistic regression model has been used. We 
used logistic model keeping aloof probit model due to large sample size $(\mathrm{n}=1212)$ since logistic model is preferred for large sample [6].

Estimated results from multivariate logistic regression model are presented in Table 4. From Table 4, it is apparent that Household Size, Dependency Ratio, Household Ownership of Landed Assets and Per Capita Monthly Income are statistically significant. Though, some of the explanatory variables are found not to be statistically significant, they have the expected signs.

Table 4: Summary results from logistic regression model for the effect of explanatory variables on food insecurity

\begin{tabular}{|c|c|c|}
\hline Variables & $\begin{array}{c}\text { Estimated Coefficient } \\
(\widehat{\boldsymbol{\beta}})\end{array}$ & $\begin{array}{c}\text { Marginal Effect at Mean } \\
(\text { MEM) }\end{array}$ \\
\hline \multicolumn{3}{|l|}{ Sex of Household Head } \\
\hline$\left[\right.$ Female $\left.^{\mathrm{a}}\right]$ & - & - \\
\hline [Male] & -0.347 & -0.09 \\
\hline \multicolumn{3}{|l|}{ Household Size } \\
\hline [Less than $\left.5^{\mathrm{a}}\right]$ & - & - \\
\hline$[5-6]$ & $0.441 * * *$ & $0.11^{* * *} *$ \\
\hline [Above 6] & $0.599 * * *$ & $0.15^{* * *}$ \\
\hline \multicolumn{3}{|l|}{ Access to (VGD/VGF/FFA) } \\
\hline$\left[\mathrm{No}^{\mathrm{a}}\right]$ & - & - \\
\hline [Yes] & -0.059 & -0.01 \\
\hline \multicolumn{3}{|l|}{ Access to Electricity } \\
\hline$\left[\mathrm{Yes}^{\mathrm{a}}\right]$ & - & - \\
\hline$[\mathrm{No}]$ & 0.216 & 0.05 \\
\hline Dependency Ratio & $0.332 * * *$ & $0.08 * * *$ \\
\hline Average Schooling Years of Households & -0.031 & -0.007 \\
\hline \multicolumn{3}{|l|}{ Household Ownership of Landed Assets } \\
\hline [Landless ${ }^{\mathrm{a}}$ ] & - & - \\
\hline [Small farmers (0.05-2.49 acres)] & $-0.394 * *$ & $-0.10 * *$ \\
\hline [Medium and large farmers $(>2.49$ acres $)]$ & $-0.878 * * *$ & $-0.22 * * *$ \\
\hline \multicolumn{3}{|l|}{ Occupation of Household Head } \\
\hline [Agriculture $^{\mathrm{a}}$ ] & - & - \\
\hline [Laborer] & 0.140 & 0.03 \\
\hline [Service] & 0.321 & 0.07 \\
\hline [Business] & 0.256 & 0.06 \\
\hline [Others] & 0.218 & 0.05 \\
\hline \multicolumn{3}{|l|}{ Per Capita Monthly Income } \\
\hline [Income $<\mathrm{Tk} .1178^{\mathrm{a}}$ ] & - & - \\
\hline$[$ Income $\geq$ Tk. 1178] & $-0.939 * * *$ & $-0.23 * * *$ \\
\hline Intercept & 0.57 & \\
\hline -2log-likelihood & 1492.522 & \\
\hline McFadden's $\mathbf{R}^{2}$ & 0.11 & \\
\hline
\end{tabular}

The result shows positive and significant influence of household size on household food insecurity. Marginal effect at mean (MEM) turns out households with 5-6 members and more than 6 members are about $11 \%$ and $15 \%$ more likely to be food insecure, respectively than the reference group keeping all explanatory variables at their mean. This result is consistent with other findings [7]. Household size, perhaps exerts more pressure on consumption than production for the households.

Estimated coefficient of dependency ratio is highly significant and has expected sign. That is, dependency ratio and food insecurity are closely and positively associated and food insecurity is higher among households having with children and senior citizens $\left(\right.$ age $65^{+}$). This result is consistent with other findings[8]. The MEM suggests that keeping all explanatory variables at their mean, for an increase in one unit of dependency ratio, the likelihood of the households of being food insecure is increased by $8 \%$.

Ownership of agricultural land is also found to be one of the important factors for reducing food insecurity. MEM suggests that small farmers (ownership of 0.05-2.49 acres of land) and medium and large farmers (> 2.49 acres) are $10 \%$ and $22 \%$ less likely to be food insecure, respectively than the landless households keeping all explanatory variables at their mean. The result is consistent with other findings [9].

Again, estimated coefficient of per capita monthly income is found to be an important determinant of food insecurity. From the MEM it can be said that keeping all explanatory variables at their mean, household with per capita monthly income more than Tk. 1178 (median monthly income of households) are 23\% less likely to be food insecure than that of referred category.

However, to evaluate the extent of a fitted binary logistic model to distinguish observed food insecure $(\mathrm{Y}=1)$ and food secure $(\mathrm{Y}=0)$, we can use the Receiver Operating Characteristic curve (ROC) and the area under 
the ROC curve. Fig. 1 reveals that the area under the ROC curve is as 0.7197 . This suggest that the model which is fitted, is fairly discriminating [10].

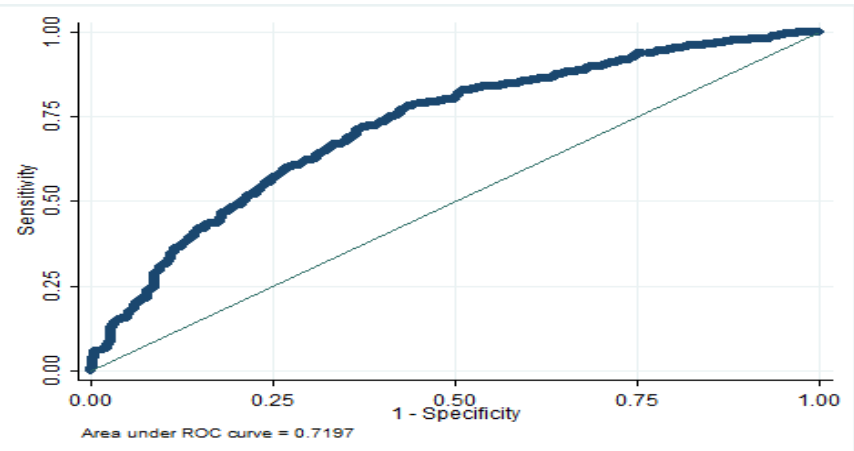

Figure1: ROC curve for logistic regression model

\section{Concluding Remarks}

From this study, some factors have been found which affect household's food security situation. For policy making, these factors may serve as important building blocks. From this study it is clear that sufficiency in food alone doesn't guarantee an end of hunger. We need to focus on food grain production with many other policy issues. Household income must be augmented by creating more employment opportunities, through education and training so that per capita monthly income can increase in our countryside. Increased income of households can improve household food security in terms of improved access to food. Special care should be taken for the landless and functionally landless and also for marginal farmers as they are more likely to be food insecure. More care should be taken for children (malnutrition), women and senior citizens $\left(64^{+}\right.$age) to reduce their level of food and health insecurity.

Improvement in production of rice has remained almost isolated. Other major food items, such as, wheat, sugarcane and pulses etc. are lagging behind. We should take measures to grow more other major food items along with rice. Moreover, it is necessary to change land -use pattern for crop diversification.

Farmers, moreover, face severe problems in having quality seeds. Only $18 \%$ of required seeds are met by truthfully labeled seeds(TLS). More attention is required to sort this problem out.

Last, but not the least, climate change impact has several after effects on agriculture, water availability, production of fisheries, sanitation \& hygiene problems etc. In such a circumstance, greater R\&D thrust is required for boosting up agricultural and rural development and food security.

\section{References}

[1] Islam, A. K. M. N., Mukta, Z.H., Institutional and Policy Failures Ignite Food Price Manipulation in Bangladesh, Campaign For Sustainable Rural Livelihood (CSRL), 2011, Dhaka.

[2] GoB/FAO, Towards a food secure Bangladesh: Country Programming framework of Bangladesh 2010-2015, 2011.

[3] Smith, Lisa C., and Ali Subandoro, Measuring Food Security Using Household Expenditure Surveys. Food Security in Practice technical guide series. Washington, D.C., International Food Policy Research Institute (IFPRI), 2007

[4] Rahman P.M.M., Matsui N., Ikemoto Y., The chronically poor in Rural Bangladesh: livelihood constraints and capabilities (1 ${ }^{\text {st }}$ edn., Routledge, London, 2009).

[5] Hosmer, D.W., Lameshow, S., Applied Logistic Regression, (2 ${ }^{\text {nd }}$ edition, ISBN: 0-471-72214-6, John Wiley \& Sons,Inc. 2000)

[6] Cakmakyapan, S., Goktas, A., A comparison of binary logit and probit models with simulation study, Journal of Social and economic Statistics, Vol. 2, No.1, 2013

[7] Bashir, M.K., Schilizzi, S. and Pandit, R., The Determinants of Rural Household Food Security for Landless Households of the Punjab, Pakistan; Working Paper 1208, 2012, School of Agricultural and Resource Economics, University of Western Australia.

[8] Maharjan, K., Joshi, N., Determinants of household food security in Nepal: A binary logistic regression analysis, Journal of Mountain Science, Vol.8, Issue 3, 2011, PP 403-413

[9] Faridi,R., Wadood, N., An Econometric assessment of household food security in Bangladesh, The Bangladesh Development Studies, Vol. XXXIII, No.3. 2010

[10] Kleinbaum, D.G., Klein, M., Logistic Regression: A self-learning text $\left(3^{\text {rd }}\right.$ edn., Springer, NY, 2010) 